\title{
Dynamics of suicide in Turkey: an empirical analysis
}

Mert Akyuz, ${ }^{1}$ Cagin Karul ${ }^{2}$ and Saban Nazlioglu ${ }^{3}$

${ }^{1}$ Department of Economics, Ankara Yildirim Beyazit University, Ankara, Turkey. ${ }^{2}$ Department of Econometrics; ${ }^{3}$ Department of International Trade and Finance, Pamukkale University, Denizli, Turkey (Correspondence to: Cagin Karul: ckarul@pau.edu.tr).

\begin{abstract}
Background: Suicide has become a public mental health problem in Turkey, with the number of deaths increasing: in 1974, the suicide rate was $1.92 \%$ for males and $1.31 \%$ for females; in 2013 this had risen to $6.22 \%$ for males and $2.26 \%$ for females.

Aims: This study attempts to empirically investigate the behaviour of suicide in Turkey by focusing on sex and cause. We pay special attention to the role of structural shifts in suicide ratios, which may have arisen from the structural changes in Turkish economy during last 2 decades.

Methods: We used time series analysis and employed unit root and stationarity tests for the period 1974-2013.

Results: The results show that disruption to female suicide and suicidal affairs stemmed from economic problems and business failures have a random walk process. This finding implies that shocks driven by economic issues and shocks toward the female sex have a permanent, long-term impact on suicide.

Conclusions: The implication is that the social administration needs to implement relevant, necessary suicide prevention policies for suicides occurring in the female and economic problems groups.

Keywords: suicide, unit root, structural shifts, Turkey

Citation: Akyuz M; Karul C; Nazlioglu S. Dynamics of suicide in Turkey: an empirical analysis. East Mediterr Health J. 2020;26(10):1184-1192. https:// doi.org/10.26719/emhj.20.033

Received: 04/08/18; accepted: 22/05/19

Copyright (c) World Health Organization (WHO) 2020. Open Access. Some rights reserved. This work is available under the CC BY-NC-SA 3.0 IGO license (https://creativecommons.org/licenses/by-nc-sa/3.o/igo)
\end{abstract}

\section{Introduction}

\section{Background}

Through widespread globalization, rapid urbanization and pervasive digitization, suicide has become a global issue and appears to be at the centre of the debate about the present and future development of the world (1). In recent years, determining the nature of shocks (temporary or permanent) of suicide has become very important subject for policy-makers and researchers (2-4). If suicide is stationary, shocks to suicide will have a temporary short-term effect on suicide, implying that policies established to reduce suicide over time are efficacious. In this case, government institutions should avoid adopting unnecessary suicide prevention policies since deviation from its long-run path will return it to its original equilibrium. However, if suicide follows a unit root process, then disruptions to suicide will have the permanent, long-term impact, implying that policies intended to reduce suicide over time are inefficacious. In this case, the authorities should take immediate measures aimed at suicide prevention because when suicide deviates from its long-run equilibrium, it will not return to its original path. Determining the structural changes has recently become significant for policy-makers since this provides crucial information about the impact of external and internal developments such as economic crises, institutional arrangements, regime shifts and policy changes on socioeconomic affairs. In the matter of suicide, the pres- ence of structural changes could also determine whether suicide prevention policies are actively implemented or not when needed.

Even though the crude suicide rate in Turkey has not reached a high level compared with Organisation for Economic Co-operation and Development (OECD) countries (5), it has started to become a significant public mental health problem. The issue of whether suicide prevention policies constituted by relevant authorities are efficacious or inefficacious is not yet questioned in order to understand the improvement in the mental health field. Up to now, there has been no specific research examining the nature of shocks to suicide according to sex and cause for Turkey. Given the increasing suicide rate over recent years, it is timely and important to now examine the behaviour of suicide.

The purpose of this study is to empirically examine whether shocks to suicide have a permanent or temporary impact on suicide. The unit root (stationary) hypothesis can be employed to determine whether suicide is likely to be mean reverting or not. In this context, to the best of our knowledge, there has been no empirical study examining the unit root properties of suicide in Turkey. Considering this gap in the literature, we test whether suicide by sex and cause in Turkey is stationary or has a unit root during the period of 1974-2013. We mainly focus on suicide by sex and cause rather than total suicide numbers since these subgroups have more explanatory characteristics for evaluating the efficaciousness of suicide prevention 
policies. In addition, the use of disaggregated data provides more reliable findings and allows specialists to implement specific suicide prevention policies for the groups most adversely affected by shocks.

\section{Literature review}

In terms of examining the nature of shocks to suicide, there are very few papers examining the integration properties of suicide in the world. A study by Yang et al. attempts to test whether suicide is stationary or nonstationary in the United States of America (USA) applying the Dickey-Fuller and Kolmogorov-Smirnov tests to annual time series data covering the period 1933-2010 and daily data for the years 1990 and 1991 (2). Their empirical findings emphasize that suicide for 6 different age groups and 4 different sex-by-race groups has unit root, suggesting that suicide prevention policies designed by decision-makers are inefficacious. Other significant research analysed the effect of the 2008 economic crisis on suicide for various age groups in the USA for quarterly data from January 1999 to December 2013 using the quantile structural break tests (3). Using these tests, the findings reveal that positive shocks statistically significantly affect suicide rates and these were non-stationary for all age groups except for the middle age group. A 2017 study examined the stochastic behaviour of the suicide rate for 23 OECD countries for the period 1961-2006 utilizing both the conventional tests (which do not account for structural changes) and the panel data testing framework with smoothing shifts (4). The findings indicate that suicide is a unit root process based on the traditional unit root tests: it is stationary in 7 out of 23 countries when the structural breaks are taken into account.

In the literature on Turkey, the dynamics of suicides are investigated from different perspectives. Altinanahtar and Halicioglu examined the determinants of suicide in Turkey for the period 1974-2007 and found that the most important factor having a crucial effect on suicide was the urbanization rate for the country (6). Alptekin et al. investigated the suicide-unemployment link spanning 1974-2007 and found that suicide was positively related to the unemployment rate (7). Durğun and Durğun examined the relationship between the crude suicide rate and income from 1975 to 2015 and found a negative impact of income increases on suicide (8).

Some more recent studies have focused on spatial analysis in order to determine the drivers and dynamics of suicide within the context of regional economics. Aktaş and Kantar applied the spatial statistical techniques and mapping tools for the period 2002-2011 (9). They found that suicide is higher in males than in females and suicide rates are influenced by seasonal conditions. The mapping tools analysis moreover indicated that Eastern Anatolia, South-eastern Anatolia, South-western Aegean and sub regions located in the West and Central Black Sea regions have higher suicide rates for both males and females compared with other regions. Yakar et al. scrutinized regional differences and developments for suicide in Turkey during the 1974-2013 period (10).
Their spatial analysis, which took into account regional differences, indicated that differences in suicide rates among the regions are reducing over time.

\section{Methodology}

The common approach for analysing the nature of shocks is to carry out unit root analysis. The econometric analysis starts with the conventional (no-shift) regression model given by

$$
\Delta \mathrm{y}_{\mathrm{t}}=\mathrm{Z}_{\mathrm{t}}^{\prime} \delta+\alpha \mathrm{y}_{\mathrm{t}-1}+\varepsilon_{\mathrm{t}}[1]
$$

where $t=1, \ldots T$ is time dimension, $\Delta$ is the firstdifference operator, $\varepsilon_{t}$ is independently and identically distributed error term with zero mean and homoscedastic variance $\left(\sigma_{\varepsilon}^{2}\right)$ and $Z_{t}$ includes the deterministic terms which is defined as $Z_{\mathrm{t}}=$ [1] for the constant model and $Z_{t}=[1, t]^{\prime}$ for the constant and trend model. The unit root null hypothesis $\left(\mathrm{H}_{\mathrm{O}}: \alpha=0\right)$ is tested against the stationarity alternative $\left(\mathrm{H}_{1}: \alpha<0\right)$. The $\tau$ statistic developed by Dicker and Fuller is the t-ratio of $\alpha$ (11). Testing the stationarity null hypothesis instead of unit root is useful to confirm results from tests with a stationarity alternative (12). In equation [1], the null hypothesis of stationarity $\left(\mathrm{H}_{0}: \alpha<0\right)$ is tested against the alternative hypothesis of unit root $\left(\mathrm{H}_{1}: \alpha=0\right)$. The so-called KPSS statistic developed by Kwiatkowski et al. is defined as:

$$
L M=\frac{\sum_{t=1}^{T} \tilde{S}_{t}^{2}}{\widetilde{\sigma}_{\varepsilon}^{2}}
$$

where $\tilde{S}_{t}=\sum_{j=1}^{t} \tilde{\varepsilon}_{j}$ is the partial sum of OLS residuals from the regression $y_{\mathrm{t}}$ on $Z_{\mathrm{t}}$, and $\tilde{\sigma}_{\varepsilon}^{2}$ is the estimated longrun variance of $\varepsilon_{t}$ given by:

$$
\sigma_{\varepsilon}^{2}=\lim _{T \rightarrow \infty} T^{-1} E\left(S_{T}^{2}\right)
$$

where $\mathrm{T}$ is the sample size (13).

It is assumed that $Z_{\mathrm{t}}$ does not to have any structural changes in the no-shift model, but ignoring structural shifts leads to low power in the $\tau$ statistic (14) and size distortions in the KPSS test (15). In order to allow a sharpshift (sudden) change, $Z_{t}$ is described as $\left[1, D_{t}\right]^{\prime}$ for the level shift model and as $\left[1, t, \mathrm{DU}_{t}, \mathrm{DT}_{\mathrm{t}}\right]^{\prime}$ for the trend shift model where $D_{t}$ is the dummy variable for level shift, defined as $\mathrm{DU}_{t}=0$ for $\mathrm{t} \leqslant \mathrm{T}_{\mathrm{B}}$ and 1 otherwise, and $\mathrm{DT}_{\mathrm{t}}$ is the dummy variable for trend shift, defined as $\mathrm{DT}_{t}=0$ for $t \leqslant T_{B}$ and $t-T_{B}$ otherwise, where $T_{B}$ shows the break dates. Zivot and Andrews (ZA) allow one break under the unit root null hypothesis (16) and Kurozumi allows a break under the stationarity null hypothesis (17).

The sharp-shift models are based on the dummy variable approach, which entails knowing a priori the number, dates and form of breaks. In practice, it is difficult to have this information and moreover economic 
series may contain multiple smooth breaks at unknown dates. For the stationarity analysis, Becker, Enders and Lee (BEL) use a Fourier approximation for $\mathrm{Z}_{\mathrm{t}}$ which does not require selecting the dates, number and form of the breaks (12). The Fourier expansion for $Z_{t}$ is described as:

$$
\left[1, \sin \left(\frac{2 \pi k t}{T}\right), \cos \left(\frac{2 \pi k t}{T}\right)\right]
$$

for the level shift model and as:

$$
\left[1, t, \sin \left(\frac{2 \pi k t}{T}\right), \cos \left(\frac{2 \pi k t}{T}\right)\right]
$$

for the trend shift model, where $k$ represents an integer frequency. Enders and Lee (EL) recently developed an augmented Dickey-Fuller (ADF)-type unit root statistic by employing a Fourier approximation (18).

\section{Results}

\section{Data}

Data for the period 1974-2013 were retrieved from the Turkish Statistical Institute (19). This data resource breaks down suicides according to sex and reason for each year. The economic problems and business failure series do not note the sex, i.e. they were accumulated and classified according to reason only. Similarly, female suicides were collected and classified without noting any reason. The descriptive statistics in Table 1 show that the mean suicide rate among males is slightly higher than that of females. This difference may be attributed to the fact that economic problems and unemployment have a more deleterious effect on the living conditions of males (as breadwinners). The descriptive analysis clearly indicates that the mean suicide rate in the study time period is around 1.5 per 100000 population.

With respect to suicide by cause, suicide in illness has a higher average rate than suicide for other causes.
Education failure has the lowest suicide level. The normality assumption for all series is also not rejected by the JB (Jarque-Bera) normality test (20). To visualize the dynamics of suicides, we depicted our data with their smoothing changes (Fourier approximations) (Figure 1.) It can clearly be seen that the Fourier approximation is very successful in capturing the dynamics of series. The figures also show that the nature of shifts in series is generally unknown, and there are no specific guides regarding number and date of breaks.

\section{Empirical results}

We first concentrated on examining the suicide shocks by sex and report the results in Table 2 . The results from the ADF test show that suicide shocks are permanent for both sexes in the no-shift model. When the one-sharp break is accounted for in the unit root procedure, the ZA test indicates that shocks have a permanent, long-term effect on suicide for females. Among the stationarity tests, the KPSS test rejects the null hypothesis of stationarity for male and female in the constant model. The Kurozumi test with a sharp-shift supports the evidence on stationarity for both male and female. The shifts obtained by new types of unit root tests allocate important information about the time of policy implementations and random shocks. On scrutinizing the break points, it is clearly observed that, in the number of suicides in Turkey, structural breaks occurred prior to the 2000-2001 crisis. Moreover, when the structural changes are modelled as a gradual/smooth process by means of a Fourier approximation, the EL and BEL tests provide evidence in favour of the fact that shocks to suicide have a permanent, long-term impact on suicide for females.

We further investigated the dynamics of suicide shocks by cause (Table 3 ). The traditional ADF unit root test shows that all series have a unit root except for "other" causes. The ZA test (which is based on the sharp-shift model) demonstrates that family incompatibility with the level shift and economic

\begin{tabular}{|c|c|c|c|c|c|c|c|}
\hline Characteristic & Mean & SD & Median & Maximum & Minimum & $\mathrm{JB}^{a}$ & P-value \\
\hline \multicolumn{8}{|l|}{ Sex } \\
\hline Male & 1102.9 & 597.7 & 886 & 2377 & 366 & 4.030 & 0.133 \\
\hline Female & 621.7 & 257.3 & 528 & 1131 & 243 & 3.284 & 0.194 \\
\hline \multicolumn{8}{|l|}{ Cause } \\
\hline Illness & 456.0 & 202.1 & 469 & 1018 & 61 & 0.991 & 0.609 \\
\hline Family incompatibility & 312.6 & 145.7 & 293 & 644 & 96 & 1.576 & 0.455 \\
\hline $\begin{array}{l}\text { Economic problems \& } \\
\text { business failure }\end{array}$ & 228.7 & 153.3 & 212.5 & 673 & 21 & 2.821 & 0.244 \\
\hline Emotional relationship & 132.0 & 73.7 & 133 & 314 & 18 & 1.390 & 0.499 \\
\hline Educational failure & 39.0 & 26.3 & 33.5 & 95 & 2 & 3.395 & 0.183 \\
\hline Other & 123.5 & 67.6 & 109.5 & 260 & 21 & 3.385 & 0.184 \\
\hline
\end{tabular}
problems with the trend shift have a unit root process.

SD = standard deviation.

ajarque and Bera normality test.

$P$-value is the probability of JB statistic. 


\section{Figure 1 Dynamics of suicides with their smooth shift (Fourier) approximations}

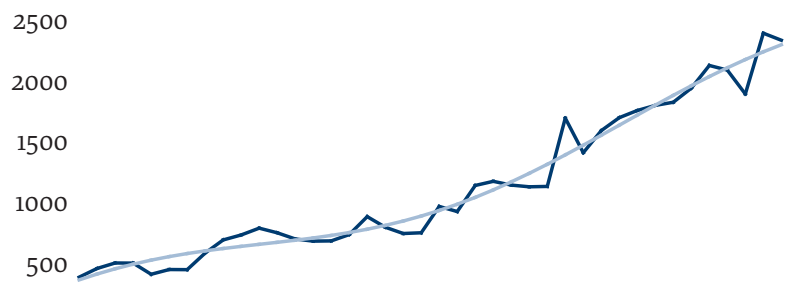

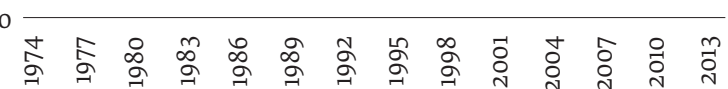
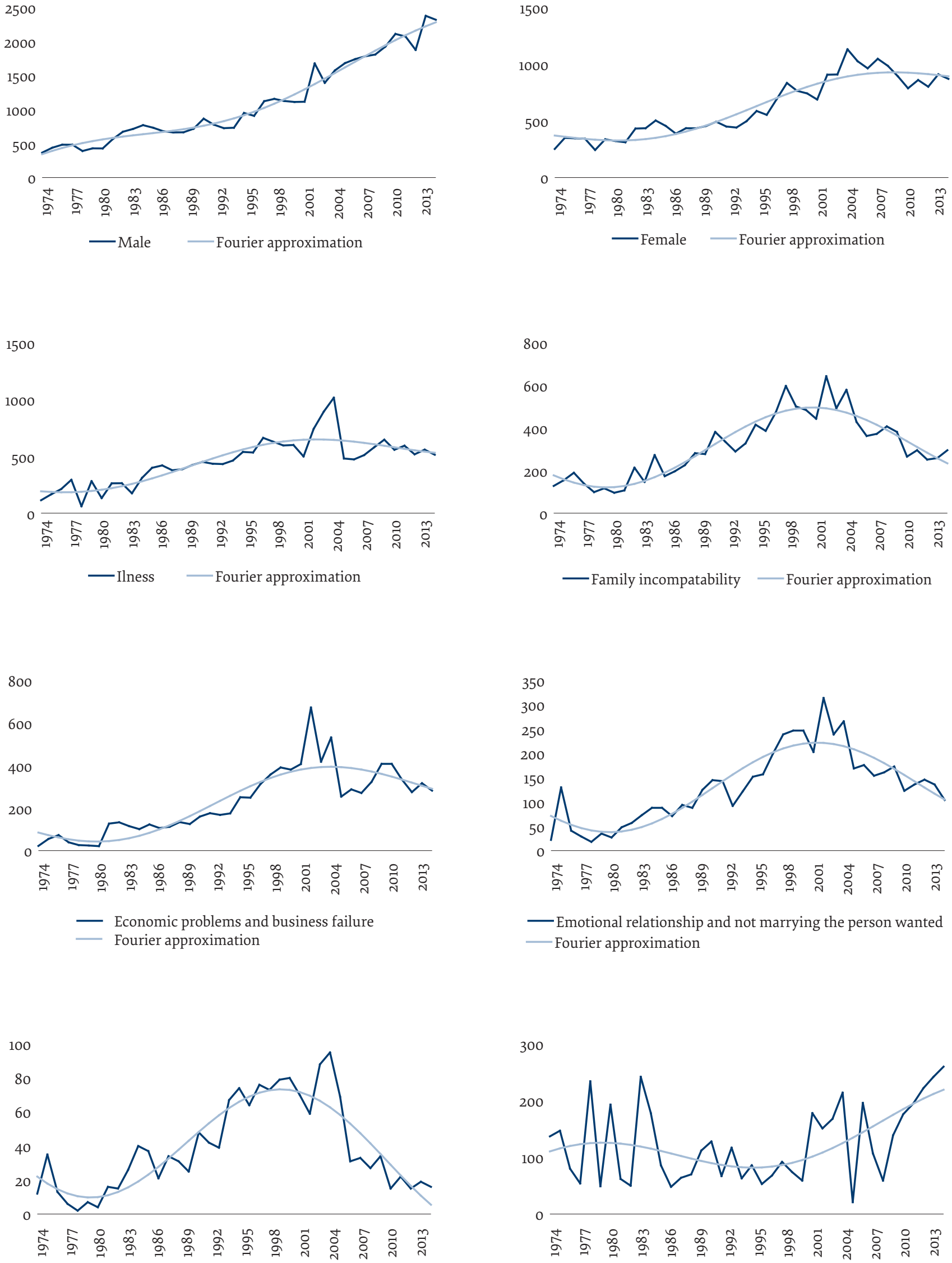

300

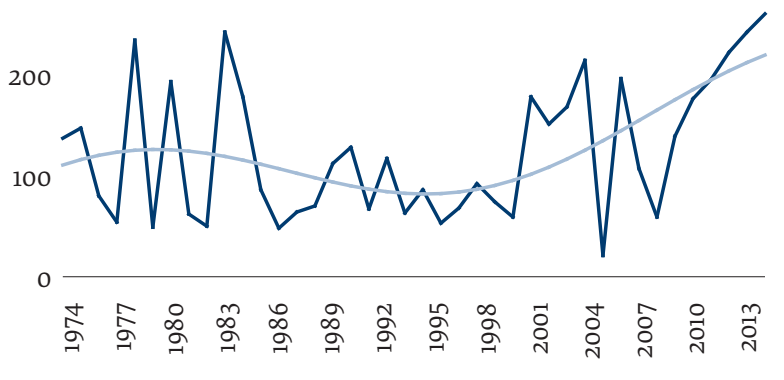

—Educational failure — Fourier approximation 


\begin{tabular}{|c|c|c|c|c|c|c|c|c|}
\hline \multirow[t]{3}{*}{$\operatorname{Sex}$} & \multirow{2}{*}{\multicolumn{2}{|c|}{ No-shift }} & \multirow{2}{*}{\multicolumn{3}{|c|}{$\begin{array}{l}\text { Sharp-shift } \\
\text { Unit root tests }\end{array}$}} & \multirow{2}{*}{\multicolumn{3}{|c|}{ Smooth-shift }} \\
\hline & & & & & & & & \\
\hline & ADF & Sign & $\mathbf{Z A}$ & Sign & Break date & EL & Sign & $\mathbf{k}^{\mathbf{c}}$ \\
\hline \multicolumn{9}{|c|}{ Constant model } \\
\hline Male & 1.097 & & -4.825 & * & 1999 & -0.146 & & 1 \\
\hline Female & -1.318 & & -3.573 & & 1994 & -3.007 & & 1 \\
\hline \multicolumn{9}{|c|}{ Constant and trend model } \\
\hline Male & -1.546 & & -6.513 & *** & 1990 & -6.051 & $* * *$ & 1 \\
\hline \multirow[t]{3}{*}{ Female } & -2.354 & & -4.673 & & 1999 & -3.521 & & 1 \\
\hline & \multicolumn{8}{|c|}{ Stationarity tests ${ }^{\mathrm{b}}$} \\
\hline & KPSS & Sign & Kurozumi & Sign & Break date & BEL & Sign & $\mathbf{k}^{\mathbf{c}}$ \\
\hline \multicolumn{9}{|c|}{ Constant model } \\
\hline Male & 0.593 & ** & 0.138 & & 2000 & 0.332 & $* * *$ & 1 \\
\hline Female & 0.549 & ** & 0.126 & & 1995 & 0.268 & ** & 1 \\
\hline \multicolumn{9}{|c|}{ Constant and trend model } \\
\hline Male & 0.179 & ** & 0.069 & & 2000 & 0.031 & & 1 \\
\hline Female & 0.084 & & 0.073 & & 2000 & 0.060 & ** & 1 \\
\hline
\end{tabular}

Sign = significance: ${ }^{* * *}=1 \%,{ }^{* *}=5 \%$ and ${ }^{*}=10 \%$.

a Based on t-stat significance rule as in Zivot and Andrews (16).

${ }^{b}$ Based on Bartlett kernel with Kurozumi (17) rule.

'Based-on on minimizing sums of squared residuals (see 14).

In what follows, $d_{t}$ is [1] for constant model and [1,t] for constant and trend model: ADF: $\Delta y_{t}=d_{t}^{\prime} \theta+\alpha y_{t-1}+\sum_{j=1}^{p} \beta_{j} \Delta y_{t-j}+\varepsilon_{t}$.

The critical values (CVs) are $-3.61(1 \%),-2.94(5 \%),-2.60$ (10\%) (constant model), and $-4.21(1 \%),-3.53(5 \%),-3.20$ (10\%) (constant and trend model).

ZA: $\Delta y_{t}=d_{t}^{\prime} \theta+\mu_{1} D U_{t}+\varphi_{1} D T_{t}+\alpha y_{t-1}+\sum_{j=1}^{p} \beta_{j} \Delta y_{t-j}+\varepsilon_{t}$

The CVs are: $-5.34(1 \%),-4.80(5 \%),-4.58(10 \%)$ (constant model) [Table 2, (16):256], and -5.57 (1\%), -5.08 (5\%), -4.82 (10\%) (constant and trend model) [Table 4, (16):257].

EL: $\Delta y_{t}=d_{t}^{\prime} \theta+\varphi_{1} \sin (2 \pi k t / T)+\varphi_{2} \cos (2 \pi k t / T)+\alpha y_{t-1}+\sum_{j=1}^{p} \beta_{j} \Delta y_{t-j}+\varepsilon_{t}$.

The CVs are: -4.42 (1\%), -3.81 (5\%), -3.49 (10\%) fork = 1 (constant model) [Table 1b; EL, (13):197] and -4.95 (1\%), -4.35 (5\%), -4.05 (10\%) fork $=1$ (constant and trend model) [Table 1a; EL, (18):197]. KPSS: $y_{t}=d_{t}^{\prime} \theta+\varepsilon_{t}$

The CVs are $0.739(1 \%), 0.463(5 \%), 0.347$ (10\%) (constant model), and 0.216 (1\%), $0.146(5 \%), 0.119$ (10\%) (constant and trend model) [Table 1; KPSS, (13):166].

Kurozumi: $y_{t}=d_{t}^{\prime} \theta+\mu_{1} D U_{t}+\varphi_{1} D T_{t}+\varepsilon_{t}$

The CVs are $1.074(1 \%), 0.748(5 \%), 0.607$ (10\%) (constant model) [Table 2, Case 0; Kurozumi, (17):76], and 0.329 (1\%), 0.247 (5\%), 0.211 (10\%) (constant and trend model) [Table 2, Case 3; Kurozumi, (17):76].

BEL: $y_{t}=d_{t}^{\prime} \theta+\varphi_{1} \sin (2 \pi k t / T)+\varphi_{2} \cos (2 \pi k t / T)+\varepsilon_{t}$.

The CVs are: 0.2699 (1\%), 0.1720 (5\%), 0.1318 (10\%) (constant model), and $0.0716(1 \%), 0.0546(5 \%), 0.0471$ (10\%) (constant and trend model) [Table 1a; BEL, (12):389].

With regard to smooth/gradual shifts derived from the Fourier approximation, the EL test supports evidence on the stationarity of suicide for economic problems and business failure, implying that shocks to suicide rested on permanent economic difficulties. The no-shift stationarity test (KPSS) rejects the null of stationarity for all series except for educational failure with constant and economic problems with constant and trend, whereas the sharp-shift stationarity model by Kurozumi indicates that all series are stationary. For the Fourier-based stationarity tests, the gradual-shift BEL model maintains that suicide for economic problems and business failure is not mean reverting according to both the level and trend shift models, implying that shocks to this cause of suicide have a long-lasting effect.

\section{Discussion}

The number of suicides in Turkey has been increasing since 1974 but compared to European Union or OECD levels they have not yet shown a tendency to an upward trend. Besides the number of suicides, suicide occurrence has been more likely to converge in Turkey, meaning that differences between regions have slowly disap- peared. Higher suicide rates for both males and females, nevertheless, are seen in East Anatolia, South-eastern Anatolia, South-western Aegean and sub-regions located in the West and Central Black Sea regions compared with other regions. With the social transformation in the last quarter of the 2oth century, the rural population has rapidly and intensely migrated to the larger cities. Thus, one of the factors that has caused the increase in suicide rates during this period is urbanization. In addition, unemployment and income are the main macroeconomic factors which have had an impact on the rise in suicides. Being unemployed and earning a low income has been a trigger for suicide in Turkey as in other countries. Finally, divorce rates due to social factors have been among the fundamental catalysts of the increase in suicide rates in Turkey. This social factor, specifically, makes living conditions tougher for females day by day, and the process results in suicide among divorced females $(6-10)$.

From our descriptive analysis, the mean suicide rate in the study time period is around 1.5 per 100000 population, which is a lower rate than in other Islamic countries. In Islamic societies like Turkey, where there is a high level of stigma and certain legal barriers, suicide is considered haram (forbidden by religious faith) behaviour, and the 


\begin{tabular}{|c|c|c|c|c|c|c|c|c|}
\hline \multirow[t]{3}{*}{ Cause } & \multirow{2}{*}{\multicolumn{2}{|c|}{ No-shift }} & \multirow{2}{*}{\multicolumn{3}{|c|}{$\begin{array}{l}\text { Sharp-shift } \\
\text { Unit root tests }\end{array}$}} & \multirow{2}{*}{\multicolumn{3}{|c|}{ Smooth-shift }} \\
\hline & & & & & & & & \\
\hline & ADF & Sign & $\mathbf{Z A}$ & Sign & Break date & EL & Sign & $\mathbf{k}$ \\
\hline \multicolumn{9}{|l|}{ Constant model } \\
\hline Illness & -1.399 & & -6.341 & *** & 2002 & -4.267 & ** & 1 \\
\hline Family incompatibility & -1.418 & & -4.265 & & 2002 & -5.672 & *** & 1 \\
\hline Economic problems & -1.425 & & -4.827 & * & 2002 & -3.199 & & 1 \\
\hline Emotional relationship & -1.076 & & -5.091 & ** & 2003 & -5.253 & $* * *$ & 1 \\
\hline Educational failure & -1.736 & & -5.337 & $* * *$ & 2003 & -3.796 & * & 1 \\
\hline Other & -4.779 & $* * *$ & -6.797 & $* * *$ & 1984 & -3.458 & * & 1 \\
\hline \multicolumn{9}{|l|}{ Constant and trend model } \\
\hline Illness & -3.275 & * & -7.147 & $* * *$ & 2000 & -5.312 & $* * *$ & 1 \\
\hline Family incompatibility & -0.869 & & -5.649 & $* * *$ & 1999 & -5.597 & $* * *$ & 1 \\
\hline Economic problems & -1.571 & & -4.816 & & 2002 & -3.536 & & 1 \\
\hline Emotional relationship & -0.863 & & -6.744 & *** & 2002 & -5.126 & $* * *$ & 1 \\
\hline Educational failure & -1.429 & & -6.005 & *** & 2003 & -4.100 & * & 1 \\
\hline \multirow[t]{3}{*}{ Other } & -5.267 & $* * *$ & -6.814 & *** & 2005 & -3.860 & & 1 \\
\hline & \multicolumn{8}{|c|}{ Stationarity tests } \\
\hline & KPSS & Sign & Kurozumi & Sign & Break date & BEL & Sign & $\mathbf{k}$ \\
\hline \multicolumn{9}{|l|}{ Constant model } \\
\hline Illness & 0.506 & ** & 0.157 & & 2003 & 0.2877 & $* * *$ & 1 \\
\hline Family incompatibility & 0.362 & * & 0.095 & & 2004 & 0.0591 & & 1 \\
\hline Economic problems & 0.497 & ** & 0.125 & & 2003 & 0.1769 & ** & 1 \\
\hline Emotional relationship & 0.386 & * & 0.113 & & 2003 & 0.0733 & & 1 \\
\hline Educational failure & 0.220 & & 0.107 & & 2004 & 0.1314 & & 1 \\
\hline Other & 0.421 & * & 0.104 & & 1984 & 0.1914 & ** & 1 \\
\hline \multicolumn{9}{|l|}{ Constant and trend model } \\
\hline Illness & 0.174 & ** & 0.130 & & 2003 & 0.033 & & 1 \\
\hline Family incompatibility & 0.136 & * & 0.069 & & 1996 & 0.048 & * & 1 \\
\hline Economic problems & 0.113 & & 0.039 & & 1996 & 0.050 & * & 1 \\
\hline Emotional relationship & 0.125 & * & 0.063 & & 1996 & 0.059 & ** & 1 \\
\hline Educational failure & 0.140 & * & 0.167 & & 2004 & 0.045 & & 1 \\
\hline Other & 0.226 & $* \star *$ & 0.062 & & 1999 & 0.034 & & 1 \\
\hline
\end{tabular}

Notes: Same as for Table 2.

low rate of suicide registration may have a significant effect on the study results. There has been limited research on the impact of religion on suicide for Middle Eastern countries since suicide has not been reported to the international institutions. However, a few Islamic countries have recorded and reported suicide rates in the region (21) and Turkey is one of them. Suicide mortality data has been recorded by health administrations and statistical institutions and distributed officially in Turkey for researchers.

The labour force participation rate in Turkey decreased from $58.8 \%$ in 1989 to $50.8 \%$ in 2013 . For males, it has fallen from $80.6 \%$ to $71.5 \%$; for females, the numbers have become worse than for males over time. In fact, Turkey has exceptionally been suffering from the problem of a low female labour force participation rate for a long time: the rate declined from $36.3 \%$ in 1989 to $23.6 \%$ in 2007 , but increased slightly to $30.0 \%$ in 2013 (19). However, when compared with OECD nations, Turkey still has the lowest female labour force participation rate: $37.6 \%$ in 2017 $(22,23)$. The unemployment rate in Turkey was $8.6 \%$ in 1989 and $9.7 \%$ in 2013 , with the rate for females at $9.5 \%$ in 1989 and $11.9 \%$ in 2013 . This rose steeply during the 2009 global economic crisis, reaching $14.3 \%$ (19).

From the empirical analysis in this study, it can be concluded that suicide contains the unit root for females while it follows the stationary process for males. This finding clearly implies that shocks to suicide have a longterm permanent impact on females but a short-term temporary effect on males. The main policy implication from our results is that suicide prevention policies against shocks are efficacious for males but inefficacious for females. Considering the structural break dates, we 
have overwhelming evidence in favour of time-series, non-stationary suicide for females.

For mental health problems, social and health administration authorities have developed institutional policies and enacted laws. First, in 2006, the National Mental Health Policy was announced and published by the Ministry of Health. This programme aimed to engender community-based mental health care, provide better quality of health care services, introduce the mental health law, and increase the quality of human capital in public mental health. This set of mental health policies was put into action through the National Mental Action Plan in 2011. Second, the Ministry of Health decided to set up community mental health centres in 2009. The number of these centres increased over time and in 2015 there were 86 across Turkish cities. Third, the government signed the Convention on the Rights of Persons with Disabilities in 2009. According to this convention, people with mental disorders have equal rights to access health services and these people are recognized officially (24-26).

In 2000-2001 the most devastating economic and financial crisis hit Turkey $(27,28)$. Traditionally, economic and financial turmoil has disruptive social consequences that are endured by the vulnerable (29). Females were affected by the 1999-2000 economic depression (structural break occurring particularly in 1999 and 2000) referring shock to suicide in females deviated from its long-run path, and suicide series for females have not returned to the long-run equilibrium. Hence, it is concluded that disturbance to suicide in females had a permanent effect on suicide, and suicide prevention policies introduced after 2000 have been inefficacious. In contrast, the 1999-2000 economic shock to suicide among males deviated from its long-run equilibrium but then returned to its time trending.

The empirical analysis of the causes of suicide provides a stationary process for illness, emotional relationships and not marrying the desired person, educational failure, other. On the other hand, economic problems and business failure were found to have unit root dynamics. These results mean that these causes (illness, emotional relations and not marrying the desired person, and educational failure), return to the mean or trend path after shocks whereas suicides for reasons of economic problems and business failures do not return. Reviewing the dates of breaks, it can be seen that most of the structural changes occurred between 2000 and 2004, suggesting the structural breaks accorded well with the traumatic events taking place over the analysed period. Based on our empirical evidence and the increases in health expenditure and social benefits after the 2000/2001 economic crisis, which offered generous and competitive support, it can be inferred that, except for economic problems and business failure, there might be a close link between suicide based on other reasons and social benefits; this shows that the measures taken by the new administration after 2003 have been efficacious in returning suicides to their original path. However, policies aimed at bringing about a reduction in suicide for economic problems and business failure have been inefficacious.

To sum up, the number of suicides which have occurred over the past 4 decades in Turkey and the ability to reduce this number via social and economic policies which have been specifically designed for suicide prevention cannot be overlooked.

The empirical results in this study call attention to the design and execution of suicide prevention policies for people who may be likely to attempt suicide for reasons of economic problems and business failure. Furthermore, government authorities should abstain from creating redundant suicide prevention policies for males; however, the appropriate institutions should, without delay, introduce suicide prevention policies aimed at females.

\section{Conclusion}

We employed the unit root and stationarity tests to determine the nature of shocks to suicide by sex and cause in Turkey for the annual data over the period 1974-2013. Our testing procedure particularly allows for sharp and smooth structural breaks. The findings support the evidence on unit root behaviour for suicide among females and for economic problems and business failure. These findings imply that policies and strategies performed by social decision-makers for suicide prevention in these groups have been inefficacious and much more concern should be allocated to suicide among these groups.

\section{Acknowledgement}

We would like to thank Professor Dr David Lester for his comments on the initial manuscript for this study.

Funding: None.

Competing interests: None declared. 


\section{Dynamique du suicide en Turquie : analyse empirique}

\section{Résumé}

Contexte : Le suicide est devenu un problème de santé mentale publique en Turquie, où le nombre de décès dus à des suicides est en augmentation : en 1974, le taux de suicide était de 1,92\% chez les hommes et de 1,31 \% chez les femmes ; en 2013 , il atteignait $6,22 \%$ chez les hommes et $2,26 \%$ chez les femmes.

Objectifs : Étudier empiriquement le comportement suicidaire en Turquie en fonction du sexe et des causes de suicide. Nous accordons une attention particulière au rôle des changements structurels dans les taux de suicide, qui découlent peut-être des évolutions structurelles survenues dans l'économie turque ces 20 dernières années.

Méthodes: Nous avons eu recours à l'analyse de séries temporelles et utilisé des tests de racine unitaire et de stationnarité pour la période 1974-2013.

Résultats : Les résultats montrent que les perturbations entraînant des suicides et des évènements suicidaires chez les femmes sont dus à des problèmes économiques et à des échecs professionnels et suivent un processus aléatoire. $\mathrm{Ce}$ constat signifie que les chocs causés par des problèmes économiques et ceux subis par les femmes ont des effets permanents à long terme sur le taux de suicide.

Conclusions: Ceci implique que les autorités sociales doivent mettre en œuvre des politiques pertinentes de prévention du suicide à l'intention des femmes et des groupes vulnérables sur le plan économique.

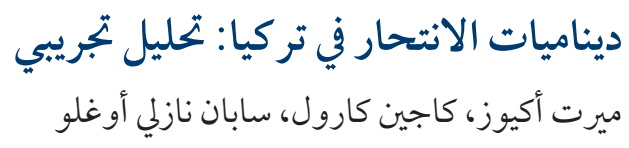

الخلاصة

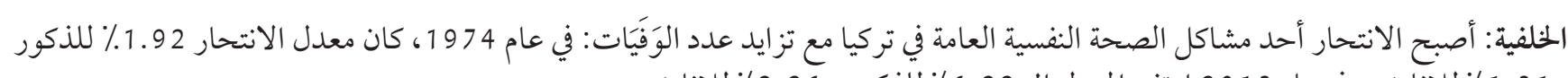

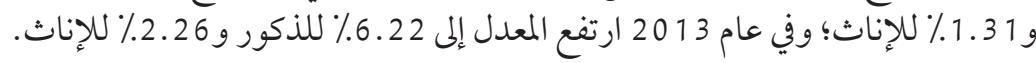

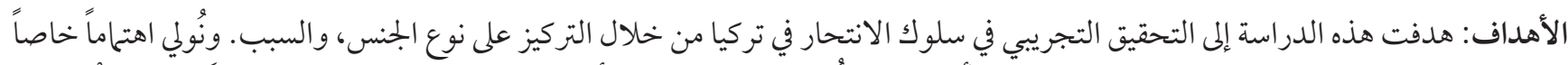

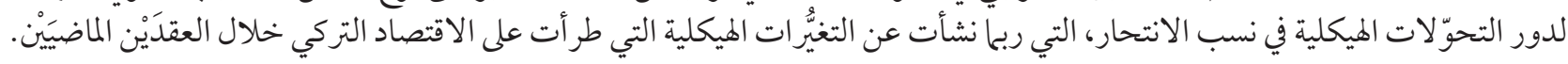

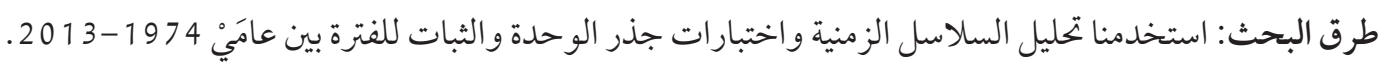

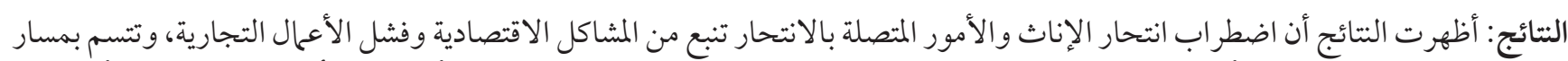

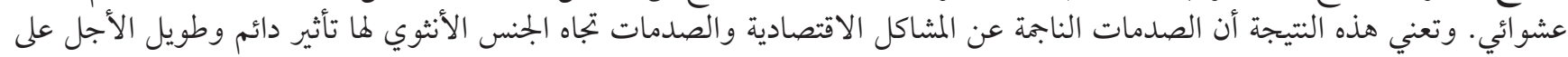
الانتحار.

الاستتاجات: يعني ذلك أن الإدارة الاجتماعية تقتضي تنفيذ سياسات مناسبة وضرورية للوقاية من الانتحار فئار فيا يتعلق بحالات الانتحار التي

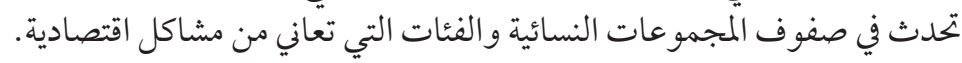

\section{References}

1. Preventing suicide: a global imperative. Geneva: World Health Organization; 2014 (http://www.who.int/mental_health/suii cide-prevention/exe_summary_english.pdf?ua=1, accessed 2 March 2020).

2. Yang B, Lester D, Lyke J, Olsen R. Is the suicide rate a random walk? Psycholog Reports. 2015;116(3):983-5. doi:10.2466/12.13. PRo.116k28w4

3. Chen W, Chang T, Lin Y. Investigating the persistence of suicide in the United States: evidence from the quantile unit root test. Social Indicators Res. 2016;135(2):813-33.

4. Chang T, Cai Y, Chen W. Are suicide rate fluctuations transitory or permanent? Panel KSS unit root test with Fourier function through the sequential panel selection method. Romanian J Economic Forecasting. 2017;20(3):5-17.

5. Suicide rates. Paris: OECD Data; 2018 (https://data.oecd.org/healthstat/suicide-rates.htm, accessed 5 March 2020).

6. Altinanahtar A, Halicioglu F. A dynamic econometric model of suicides in Turkey. J Socio-Economics. 2009;38(6):903-7.

7. Alptekin D, Alptekin V, Uysal D. A VAR analysis of the unemployment-suicide relationship in the case of Turkey within the context of anomie theory. J Academic Studies. 2010;12(44):63-85.

8. Durğun F, Durğun B. Suicide-income relationship: causal analysis for Turkey. Dicle University J Faculty Econom Administrative Sci. 2017;7(14):398-416.

9. Aktaş SG, Kantar YM. A study of suicide mortality in Turkey (2002-2011). J EU Res Business. 2016:1-16. 
10. Yakar M, Temurçin K, Kervankiran I. Suicide in Turkey: its changes and regional differences. In: Rogatka K, Szymańska D, eds, Bull Geography. Socio-economic Series. 2017;35:123-43.

11. Dickey DA, Fuller WA. Likelihood ratio statistics for autoregressive time series with a unit root. Econometrica. 1981;49:1057-72.

12. Becker R, Enders W, Lee J. A stationarity test in the presence of an unknown number of smooth breaks. J Time Series Anal. 2006;27:381-409.

13. Kwiatkowski D, Phillips PCB, Schmidt P, Shin Y. Testing the null hypothesis of stationary against the alternative of a unit root. J Econometrics. 1992;54:159-178.

14. Perron P. The great crash, the oil price shock, and the unit root hypothesis. Econometrica. 1989; 57:1361-401.

15. Lee J, Huang CJ, Shin Y. On stationary tests in the presence of structural breaks. Economics Letters. 1997;55:165-172.

16. Zivot E, Andrews DWK. Further evidence on the great crash, the oil-price shock, and the unit-root hypothesis. J Business Economics-Statistics. 1992;10:251-70.

17. Kurozumi E. Testing for stationarity with a break. J Econometrics. 2002;108(1):63-99.

18. Enders W, Lee J. The flexible fourier form and Dickey-Fuller type unit root tests. Economics Letters. 2012;117:196-9.

19. [Statistical indicators 1923-2013]. Ankara: Turkish Statistical Institute; 2018 (http://www.tuik.gov.tr/Kitap.do?metod=KitapDetl tay\&KT_ID=0\&KITAP_ID=160 accessed 5 March 2020) (in Turkish).

20. Jarque CM, Bera AK. A test for normality of observations and regression residuals. Int Statistical Rev. 1987;55(2):163-72. doi:10.2307/1403192

21. Gearing RE, Lizardi D. Religion and suicide. J Religion Health. 48(3):332-41.

22. Atasoy BS. Female labour force participation in Turkey: the role of traditionalism. European J Development Res. 2017;29(4):675706.

23. LFS by sex and age - indicators. Paris: Organisation for Economic Co-operation and Development; 2019 (https://stats.oecd.org/ Index.aspx?DataSetCode=LFS_SEXAGE_I_R\#, accessed 2 March 2020).

24. Soygür H. Community mental health services: Quo vadis? Nöro Psikiyatri Arş. 2016;53(1):1-3. doi:10.5152/npa.2016.15022016

25. Alptekin K, Duyan V. Suicide prevention: issues and suggestions. Kriz Dergisi. 2009;17(2):13-20.

26. Dogan O. Social psychiatry practices in Turkey from yesterday to today. Anadolu Psikiyatri Dergisi. 2016;17(2):136-43.

27. Özatay F. The 1994 currency crisis in Turkey. J Policy Reform. 2000;3(4):327-52

28. Özatay F, Sak G, Garber P, Ghosh A. Banking sector fragility and Turkey's 2000-01 financial crisis [with comments and discussion]. In: Brookings trade forum. Washington DC: Brookings Institution Press; 2002:121-72.

29. Risk and opportunity managing risk for development. World development report 2014. Washington DC: World Bank; 2014 (https://openknowledge.worldbank.org/handle/10986/16092, accessed 5 March 2020. 